\title{
A IMPORTÂNCIA DAS METODOLOGIAS ATIVAS DE APRENDIZAGEM PARA PROCESSO DE CONSTRUÇÃO DO CONHECIMENTO DOS ESTUDANTES DAS ESCOLAS TÉCNICAS.
}

Jacqueline Pereira dos Santos Souza, Carmen Lúcia Dias

Universidade do Oeste Paulista - UNOESTE, Mestrado em Educação, Presidente Prudente, SP. E-mail: jackps21@hotmail.com.

\section{RESUMO}

A diversidade entre gerações de estudantes nas escolas técnicas é expressiva, tornando-se importante a inovação de práticas pedagógicas que atendam suas necessidades, já que estas gerações são ativas e a maneira tradicionalizada de lecionar as desmotivam. O presente artigo teve por objetivo demonstrar a importância da inovação de práticas pedagógicas com metodologias ativas de aprendizagem em conjunto com a interdisciplinaridade no ambiente das Escolas Técnicas, visando auxiliar o processo de construção do conhecimento, por meio de um ambiente de ensino e de aprendizagem mais construcionista, contextualizado e significativo. Esta pesquisa de cunho bibliográfico teve como aporte teórico obras de referência com autores que propõem uma reflexão sobre a importância das metodologias ativas de aprendizagem conjuntamente com a interdisciplinaridade na construção do conhecimento dos educandos inseridos nas escolas técnicas. Conclui-se que as metodologias ativas de aprendizagem em conjunto com propostas interdisciplinares são importantes facilitadores na construção do conhecimento destes estudantes.

Palavras-Chave: Gerações. Metodologias ativas. Interdisciplinaridade. Construção do Conhecimento. Processo de Ensino e de Aprendizagem.

\section{THE IMPORTANCE OF ACTIVE LEARNING METHODOLOGIES FOR THE PROCESS OF CONSTRUCTION OF KNOWLEDGE OF STUDENTS OF TECHNICAL SCHOOLS.}

\begin{abstract}
The diversity between generations of students in technical schools is expressive, becoming important the innovation of pedagogical practices that meet their needs, since these generations are active and the traditional way of teaching them discourage. The aim of this article was to demonstrate the importance of the innovation of pedagogical practices with active learning methodologies in conjunction with the interdisciplinarity in the Technical Schools environment, aiming to help the process of knowledge construction, through a teaching and learning environment Constructivist, contextualized and meaningful. This bibliographical research was based on reference works with authors who propose a reflection on the importance of active learning methodologies together with the interdisciplinarity in the construction of the knowledge of the students inserted in the technical schools. It is concluded that the active learning methodologies together with interdisciplinary proposals are important facilitators in the construction of the knowledge of these students.

Keywords: Generations. Active methodologies. Interdisciplinarity. Knowledge Building. Process of Teaching and Learning.
\end{abstract}




\section{INTRODUÇÃO}

No meio educacional das escolas técnicas, existe uma grande diversidade das gerações de estudantes, abrangendo discentes desde a geração " $X$ ", " $Y$ " até a geração " $Z$ ", conhecida também como "nativos digitais" ou "milleniuns" que é formada pelos nascidos entre os anos de 1990 até aproximadamente 2009 sendo reconhecida como sucessora da geração " $\mathrm{Y}$ ", com características convenientes ao desenvolvimento tecnológico em que está inserida, onde grande parte de seu entretenimento está voltado aos games.

Tendo em vista que o processo de aprendizagem nas escolas técnicas abrange diversas gerações e que a geração " $Z$ " dos "nativos digitais" é completamente ativa, tornam-se insustentáveis no ambiente escolar as práticas pedagógicas tradicionais que se resumem em apresentação do conteúdo através da aula expositiva dialogada do professor. Esta geração gosta de se envolver e construir o conhecimento participando ativamente do processo.

Aprender é buscar, interrogar, criar, avaliar, diálogo mediato e imediato com o mundo [...] São então necessárias certas condições para que o processo se desenvolva, e isto ultrapassa largamente a concepção de um espaço pedagógico restrito a sala de aula. $O$ meio assume um importante papel como recurso educativo, mas ele só pode ser entendido se houver um aparelho conceptual que guie o aluno nessa descoberta. (CALIXTO, 1996, p.17)

Percebe-se que esta nova geração necessita, devido ao meio que está inserida, de um ambiente escolar modificado, que saia do contexto tradicional ao qual está acostumado, pois muita vezes as modificações realizadas neste meio não são suficientes para atraí-la intensamente. Como afirma Mattar (2010, p.45):

[...] apesar do discurso libertador da pedagogia moderna e de todas essas evidências, a prática da educação continua a ser fundamentalmente a mesma, com escolas orientadas por currículos ultrapassados aplicando avaliações tradicionais. Nem mesmo a educação on-line libertou-se muito do ensino tradicional.

Diante da complexidade do contexto das gerações, o ambiente das escolas técnicas que recepciona esta diversidade de alunos, composta por faixas etárias variadas em uma mesma sala de aula, ou seja, um grupo com características heterogêneas, formado por estudantes de diferentes gerações, interesses, objetivos, níveis de conhecimentos e necessidades distintas, torna-se um desafio constante para os docentes a construção do conhecimento. Pois, antigamente a educação era centrada na figura do professor, onde este era responsável pela transmissão do conhecimento e os alunos responsabilizados por sua assimilação. Dentro deste conceito, Freire (1987, p.33) afirma:

A narração, de que o educador é o sujeito, conduz os educandos à memorização mecânica do conteúdo narrado. Mais ainda, a narração os transforma em 'vasilhas', em recipientes a serem 'enchidos' pelo educador. Quanto mais vá 'enchendo' os recipientes com seus 'depósitos', tanto melhor educador será. Quanto mais se deixem docilmente 'encher', tanto melhores educandos serão. Desta maneira, a educação se torna um ato de depositar, em que os educandos são os depositários e o educador o depositante.

Nesta perspectiva, Freire nomeia este método de educação bancária, onde o educando simplesmente recebe, memoriza e repete os depósitos realizados pelo professor. Portanto: 
Eis aí a concepção de 'bancária' da educação, em que a única margem de ação que se oferece aos educandos é a de receberem os depósitos, guardálos e arquivá-los. Margem para serem colecionadores ou fichadores das coisas que arquivam. (FREIRE, 1987, p. 33).

Assim, o objetivo deste estudo está envolvido no contexto de demonstrar a importância de inovar as práticas pedagógicas por meio de metodologias ativas de aprendizagem no ambiente das escolas técnicas, tendo como propósito auxiliar o processo de construção do conhecimento dos estudantes, proporcionando um ambiente de ensino e aprendizagem mais construcionista, contextualizado e significativo.

\section{METODOLOGIA}

Esta pesquisa de cunho bibliográfico (SALVADOR, 1991), parte de uma pesquisa de mestrado, teve como aporte teórico a revisão de literatura especializada sobre o tema em algumas obras de referência que compreendem os anos entre 1999 e 2017 e um capítulo acessado no portal do MEC (2017), com autores que propõem uma reflexão sobre a importância das metodologias ativas de aprendizagem conjuntamente com a interdisciplinaridade na construção do conhecimento dos educandos inseridos nas escolas técnicas.

\section{DISCUSSÃO}

No contexto atual do ensino técnico, o docente precisa continuamente desenvolver diferentes metodologias com o propósito de atender às necessidades das diferenças de idade, de comportamento, de maturidade, e de tantas outras particularidades que cada geração possui.

Para tanto, será necessário desenvolver um ambiente em sala de aula que envolva os estudantes, visando a sua maior interação com a teoria e a prática principalmente no que tange as relações dos componentes curriculares que serão trabalhados, e neste contexto, destaca-se a interdisciplinaridade, que segundo Araújo (2014, p. 34), "Como a própria palavra diz, interdisciplinar refere-se àquilo que é comum a duas ou mais disciplinas ou campos de conhecimento."

Por sua vez, as metodologias ativas de aprendizagem podem agir como facilitadoras na construção do conhecimento dos diferentes tipos de gerações de educando presentes nas salas de aula dos cursos técnicos, já que estes têm, como proposta a contínua interação do aluno em sala de aula envolvendo a teoria x prática.

Com isso, será criado um ambiente que seja Construcionista, Contextualizado e Significativo (CCS), onde:

[...] o termo Construcionista significa a construção do conhecimento baseada na relação concreta de uma ação que produz um produto palpável (um artigo, um projeto, um objeto) de interesse pessoal de quem produz. Contextualizada, no sentido do produto ser vinculado à realidade da pessoa ou do local onde vai ser produzido e utilizado. (VALENTE, 1999, p. 135).

Em um contexto geral, um ambiente CCS, pode ser apresentado segundo Schlünzen (2000) e Schlünzen e Santos (2016), como um ambiente que consiga alcançar o empenho dos estudantes motivando-os a desenvolver suas ideias através da pesquisa e reflexão do conteúdo que está sendo trabalhado em sala de aula, tendo como auxílio o computador. O problema central para o desenvolvimento do projeto, surge em sala de aula, e este é utilizado para a compreensão das disciplinas curriculares envolvidas. Neste contexto, o professor age como mediador da aprendizagem, bem como também, no desenvolvimento do projeto. 
Assim, visa-se por meio de um ambiente construcionista, contextualizado e significativo, que o aluno utilize a máquina, ou seja, o computador como ferramenta para a construção do seu conhecimento. De tal modo que a metodologia ativa de aprendizagem no contexto interdisciplinar contribua para que o aluno tenha uma participação ativa em seu processo de aprendizagem, enquanto os professores trabalharão conjuntamente em cooperação e permuta de conhecimentos entre os componentes curriculares, sendo que a perspectiva será "a do trabalho coletivo, em que cada especialista sabe das limitações de seu campo de estudo e que a compreensão do fenômeno analisado só será possível com a articulação dos diferentes saberes" (ARAÚJO, 2014, p. 38). Quanto ao professor, Prado (2017, p. 13) complementa:

Portanto, o papel do professor deixa de ser aquele que ensina por meio da transmissão de informações - que tem como centro do processo a atuação do professor - para criar situações de aprendizagem cujo foco incida sobre as relações que se estabelecem nesse processo, cabendo ao professor realizar as mediações necessárias para que o aluno possa encontrar sentido naquilo que está aprendendo a partir das relações criadas nessas situações.

Assim, neste contexto de proposta interdisciplinar, cabe ao professor a responsabilidade de instigar os estudantes a participarem ativamente do projeto proposto, fazendo com que saiam da inatividade e se transformem em sujeitos ativos, responsáveis pela construção de seu próprio conhecimento. Pois as gerações atuais precisam de mudanças no contexto educacional, conforme afirma Moran (2000, p. 11):

Todos estamos experimentando que a sociedade está mudando nas suas formas de organizar-se, de produzir bens, comercializá-los, de divertir-se, de ensinar e aprender. O campo da educação está muito pressionado por mudanças, assim como acontece com as demais organizações.

Diante desta realidade, são adequadas as palavras de Silva (2014, p.70):

A escola, parte integrante da sociedade, reflete o que ocorre ao seu redor e, portanto, pode-se questionar até que ponto procedimentos utilizados em situações de ensino e aprendizagem estabelecidos no século XVII ainda são válidos para os alunos do século XXI. Se a sociedade mudou ao longo dos séculos, podemos pensar que também mudou o perfil dos aprendizes.

Percebe-se nas palavras do autor que a escola de maneira geral, especialmente a escola técnica, tem o desafio de inovar através de práticas pedagógicas adequadas ao perfil dos estudantes da atualidade. Sendo então, a metodologia ativa de aprendizagem por meio de projetos interdisciplinares uma proposta de implantação para as escolas técnicas, que abrangem uma diversidade de gerações de estudantes em sala de aula, com o intuito de auxiliá-los no processo de construção do conhecimento.

\section{CONCLUSÃO}

Pode-se concluir que as práticas pedagógicas, utilizadas na atualidade, ainda precisam se inovar e se adequar ao perfil dos estudantes desta última geração tecnológica. Neste contexto, as escolas técnicas precisam se ajustar ainda mais, visto que preparam o estudante para o mercado de trabalho que está altamente tecnológico. Assim, identifica-se que esta nova geração necessita cada vez mais de um ambiente escolar modificado, que saia do contexto tradicional rotineiramente visto nas instituições escolares, pois muitas vezes as mudanças realizadas neste meio não são suficientes para atraí-los intensamente. 
Portanto, os processos de ensino e de aprendizagem devem ser considerados como "práticas pedagógicas operacionalizadas por meio de conjuntos de atividades escolares propostas pelos professores com vistas a alcançar a aprendizagem de determinados conhecimentos, valores e comportamentos" (TRAVERSINI; BUAES, 2009, p. 145). Para tanto, as práticas pedagógicas utilizadas pelos docentes, precisam suscitar a motivação dos estudantes, estimulando-os continuamente para a construção do conhecimento.

Enfim, o ambiente escolar precisa ser "como um sistema de construção do saber, de enriquecimento moral e social, um espaço onde se considere cada aluno como um ser humano à procura de si próprio, em reflexão conjunta com os demais e com o mundo que o rodeia" (SILVA, 2008, p. 198-199). E para tanto se compreende que as metodologias ativas de aprendizagem conjuntamente com a interdisciplinaridade possam proporcionar um ambiente construcionista, contextualizado e significativo para os estudantes técnicos, sendo uma importante ferramenta de aprendizagem, agindo como facilitadora na construção do conhecimento dos diferentes tipos de gerações presentes nas salas de aula dos cursos técnicos, atuando continuamente na interação do aluno em sala de aula envolvendo a teoria $x$ prática, ou seja, as metodologias ativas de aprendizagem em conjunto com propostas interdisciplinares agirão nos cursos técnicos como importantes facilitadores na construção do conhecimento destes estudantes, , motivando-os para o processo de aprendizagem.

\section{REFERÊNCIAS}

ARAÚJO, U.F. Temas Transversais, pedagogia de projetos e as mudanças na educação. São Paulo: Sammus, 2014.

CALIXTO, J. A. A biblioteca escolar e a sociedade da informação. Lisboa: Caminho da Educação, 1996.

FREIRE, P. Pedagogia do oprimido. 17. ed. Rio de Janeiro: Paz e Terra, 1987.

GERHARDT, T. E; SILVEIRA, Denise Tolfo. (Org). Métodos de pesquisa. Coordenado pela Universidade Aberta do Brasil - UAB/UFRGS e pelo Curso de Graduação Tecnológica Planejamento e Gestão para o Desenvolvimento Rural da SEAD/UFRGS. - Porto Alegre: Editora da UFRGS, 2009.

MATTAR, J. Games em educação: como os nativos digitais aprendem. São Paulo: Pearson Prentice Hall, 2010.

MORAN, J. M. Ensino e aprendizagem inovadores com tecnologias audiovisuais e telemáticas. In: MORAN, J. M; MASETTO, M. M. T.; BEHRENS, M. A. Novas Tecnologias e mediação pedagógica. 8. ed. Campinas, São Paulo: Papirus, 2000.

PRADO, M. E. B. B. Pedagogia de projetos: fundamentos e implicações. Disponível em: http://portal.mec.gov.br/seed/arquivos/pdf/1sf.pdf. Acesso em: 16 jul. 2017.

SALVADOR, A.D. Métodos e técnicas de pesquisa bibliográfica. Porto Alegre: Sulina Editora, 1991. SCHLÜZEN, E. T. M.; SANTOS, D. A. N. Práticas pedagógicas do professor: abordagem construcionista, contextualizada e significativa para uma educação inclusiva. 1. ed. Curitiba: Appris, 2016. 143 p.

SCHLÜNZEN, E. T. M. Mudanças nas práticas pedagógicas do professor: criando um ambiente construcionista contextualizado e significativo para crianças com necessidades especiais físicas. Tese (Doutorado), Pontifícia Universidade Católica de São Paulo, São Paulo: 2000. 
SILVA, B. D. A tecnologia é uma estratégia. Tecnologias de Educação: ensinando e aprendendo com a TIC. In: SALGADO, Maria Umbelina Caiafa; AMARAL, Ana Lúcia. (Org.). Brasília: Ministério de Educação à Distância, 2008.

SILVA, E. M. O. Como aprende o nativo digital: reflexões sob a luz do conectivismo. Revista Intersaberes. v. 9, n. 17, p. 68-80, jan. - jun. 2014.

TRAVERSINI, C. S.; BUAES, C. S. Como discursos dominantes nos espaços da educação atravessam práticas docentes? Revista Portuguesa de Educação, v. 22, n. 2, p. 141-158, 2009. 